Jurnal Pustaka Budaya. Vol. 5, No. 2, Juli 2018

Copyright (C2018, pISSN: 2355-1186 / eISSN: 2442-7799

Available Online at: https://journal.unilak.ac.id/index.php/pb

\title{
PEMBUATAN ARCHIVAL BOX DALAM PROSES KONSERVASI NASKAH DI SUNGAI PAKNING
}

\author{
Nining Sudiar*), Rosman H.**) \\ Fakultas Ilmu Budaya Universitas Lancang Kuning, Pekanbaru, Indonesia \\ sudiar.nining@gmail.com *)rosman.panam@gmail.com**) \\ Naskah diterima: 9 April direvisi: 16 April; disetujui: 23 April
}

\begin{abstract}
Abstrak
Naskah merupakan salah satu warisan budaya yang perlu dilestarikan. Pelestarian naskah dapat dilakukan menggunakan metode sederhana, salah satunya adalah dengan menyimpannya di dalam archival box. Namun, dalam prakteknya, harga archival box di pasar cukup mahal sehingga tidak memungkinkan jika harus diadakan oleh individu pemilik naskah. Sebagai alternatif, dalam artikel ini akan dijelaskan bagaimana langkah pembuatan archival box menggunakan bahan-bahan yang mudah diperoleh. Tujuan dari penelitian ini adalah untuk mendeskripsikan bagaimana proses pembuatan archival box sebagai salah satu bentuk konservasi naskah kuno di Provinsi Riau. Metode yang digunakan adalah metode deskriptif kualitatif. Hasil penelitian menunjukkan bahwa tidak semua naskah dibuatkan wadah penyimpanan. Hanya naskah kuno yang tersimpan di rumah penduduk saja yang dibuatkan tempat penyimpanan. Pembuatan archival box dapat dilakukan menggunakan bahan-bahan sederhana seperti kertas trobos, kertas linen, dan lem. Ukuran box harus disesuaikan dengan ukuran naskah agar mempermudah ketika pembaca ingin mengeluarkan naskah dari box tersebut.
\end{abstract}

Kata kunci:archival box, naskah kuno, Riau

\begin{abstract}
Manuscript is the one of the cultural heritages that need to be conserved. Manuscript conservation can be done using a simple method, one of which is to save it in the archival box. The price of archival boxes on the market is expensive so it is not possible if it must be held by an individual owner of the script. This article will explained how to make archival boxes by self. The purpose of this study was to describe the archival box making process. The method used is qualitative descriptive method. Archival boxes can made using simple materials such as trobos paper, linen paper, and glue. The box size must be adjusted to the size of the script to make it easier when the reader wants to put it of the manuscript from the box.
\end{abstract}

Keywords: Archival box, Manuscript, Riau

\section{Pendahuluan}

Naskah atau yang juga dikenal dengan sebutan manuskrip adalah karya tulis yang dihasilkan dalam bentuk tulisan tangan (Prytherch, 2009). Pada umumnya, ketika berbicara naskah dan konservasi seringkali diidentikkan dengan istilah naskah kuno. Lebih jauh lagi, dalam konsep ilmu perpustakaan, tidak semua tulisan tangan dapat dikategorikan sebagai naskah kuno. Hanya tulisan tangan yang telah berumur 50 tahun atau lebih saja yang masuk ke dalam cakupan naskah kuno (Redaksi Penerbit Asa Mandiri, 2007). Bahkan, berdasarkan Undang-undang No. 43 tahun 2007 tentang Perpustakaan, selain berusia minimal 50 tahun, terdapat syarat tambahan bagi suatu tulisan tangan agar dapat disebut naskah kuno, yaitu memiliki nilai penting bagi kebudayaan, sejarah, dan ilmu pengetahuan (Fauzan dan Siagian, 2017). 
Namun, dalam praktiknya beberapa peneliti naskah kuno memasukkan tulisan yang belum genap berusia 50 tahun ke dalam hasil penelitian mereka. Hal tersebut sebagaimana yang telah dilakukan oleh Syukri (2012), salah satu peneliti naskah kuno dari UIN Suska Riau. Berdasarkan hasil penelitian yang telah dilakukan pada tahun 2012, Syukri memasukkan teks yang ditulis di atas kertas yang kemungkinan baru berusia 36 tahun. Hal yang serupa kemudian juga dilakukan oleh Iswanto (2015). Kedua peneliti tersebut memasukkan naskah yang masih tergolong 'muda' dikarenakan menurut mereka naskah yang ditemukan berisi teks yang ditulis menggunakan bahasa lama.

Berbicara tentang naskah kuno, maka tidak akan terlepas dari proses konservasi naskah. Konservasi merupakan proses yang dilakukan untuk memastikan bahwa suatu koleksi tetap bertahan melalui kegiatan perbaikan dan mengontrol cara penyimpanannya (Stevenson dan Collin, 2006). Konservasi penting untuk dilakukan mengingat usia dan konsidi naskah dan koleksi lainnya yang memerlukan penanganan khusus sehingga mampu bertahan lebih lama lagi.

Berbagai cara dapat dilakukan dalam rangka kegiatan konservasi. Mulai dari kegiatan pengaturan suhu ruang penyimpanan, penggunaan bahan kimia, sampai dengan penjilidan ulang (Wan Ali, 1988). Kegiatan konservasi tersebut tentu saja memerlukan dana waktu yang tidak sedikit. Hal ini menyebabkan kegiatan konservasi naskah kuno sering kali hanya dapat dilakukan oleh lembagalembaga besar dan memiliki peralatan yang memadai. Berbeda halnya dengan naskahnaskah yang tersimpan di rumah-rumah penduduk. Karena keterbatasan pengetahuan dan dana, seringkali naskah yang ada hanya disimpan dengan media seadanya saja sehingga menambah tingkat kerusakan naskah.

Melihat kondisi di atas, maka perlu usaha alternatif untuk melakukan konservasi sederhana yang murah dan mudah sehingga dapat dilakukan oleh masyarakat umum. Oleh karena itu, dalam artikel ini akan dipaparkan salah satu bagian dari kegiatan konservasi. Salah satu kegiatan yang dilakukan adalah melalui pembuatan archival box menggunakan bahanbahan yang mudah diperoleh.

Istilah Archival box merujuk kepada wadah yang terbuat dari bahan khusus untuk penyimpanan material arsip dalam jangka waktu yang lama (Pearce-Mose, 2005). Istilah tersebut kemudian berkembang tidak hanya digunakan untuk arsip saja. Tetapi juga mengacu pada box yang digunakan untuk menyimpan koleksi lain seperti buku lama, naskah kuno, dan koleksi lain yang memerlukan penanganan khusus. Pada artikel ini, material arsip yang dimaksudkan adalah naskah kuno yang berhasil ditelusuri oleh tim peneliti.

\section{Metode}

Penelitian ini dilakukan di Sungai Pakning, Bengkalis, Riau. Peralatan yang digunakan adalah kuas halus berbagai ukuran, cutting mat, gunting, cutter, penggaris, folder bone, dan pensil. Sedangkan bahan yang digunakan adalah kertas trobos 2 ukuran (3 $\mathrm{mm}$ dan $2 \mathrm{~mm}$ ), kertas linen warna hitam, , dan lem perekat.

Penelitian ini adalah penelitian kualitatif. Metode pengumpulan data dilakukan dengan pendekatan survey dan kajian pustaka. Hasil penelitian kemudian akan disajikan dalam bentuk deskriptif guna memaparkan bagaimana proses pembuatan archival box dalam proses konservasi naskah di Sungai Pakning.

\section{Hasil dan Pembahasan}

Sungai Pakning merupakan salah satu wilayah yang berada di Kabupaten Bengkalis, Provinsi Riau. Daerah ini berada terpisah berbeda pulau dengan pusat Kota Bengkalis. Satu-satunya transportasi umum yang menghubungkan wilayah tersebut adalah kapal penyebrangan ferry atau masyarakat biasa menyebutnya dengan istilah kapal Ro-Ro.

Hasil penelitian menunjukkan bahwa tidak semua naskah yang berhasil ditelusur selanjutnya dibuatkan archival box. Naskah yang dimiliki dan tersimpan di rumah-rumah penduduk berada dalam kondisi yang memprihatinkan. Kondisi tersebut dikarenakan para pemilik belum memiliki pengetahuan yang memadai tentang bagaimana cara merawat naskah kuno dengan baik Oleh karena itu, perlu dibuatkan media penyimpanan dalam bentuk archival box guna mencegah kerusakan yang lebih lanjut.

Pada dasarnya, naskah yang ditemukan di wilayah Sungai Pakning tidak dapat sepenuhnya dikategorikan sebagai naskah kuno. Hal ini dikarenakan berdasarkan hasil penelusuran, naskah yang berhasil ditemukan kemungkinan berumur di bawah 50 tahun. Naskah-naskah tersebut ditulis oleh seorang tokoh agama yang 
cukup tersohor di Sungai Pakning dan berisi tentang ajaran agama, ramuan obat tradisional, dan lain-lain. Melihat hal tersebut, disertai dengan kondisi naskah yang sudah mengalami kerusakan, maka penulis memutuskan untuk tetap melakukan konservasi guna menjaga kebertahanan naskah yang dimaksud.

Sebelum membuat archival box, tim terlebih dahulu melakukan perawatan dengan membersihkan naskah kuno. Pembersihan dilakukan menggunakan kuas khusus yang memiliki permukaan halus. Langkah ini dilakukan untuk membersihkan naskah dari kotoran berupa debu ataupun serangga yang menempel. Konservator juga diharuskan menggunakan masker dan sarung tangan latex untuk mencegah kontak langsung dengan naskah.

\section{Gambar 1 \\ Kuas Khusus untuk Membersihkan Naskah}

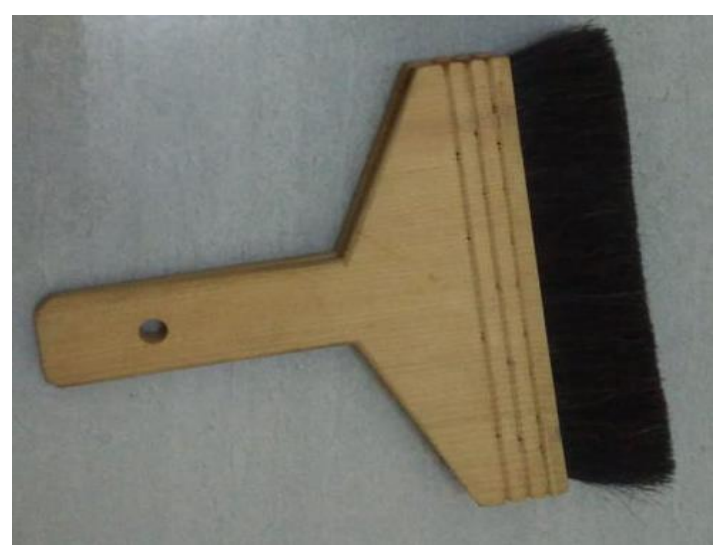

Sumber: dokumen pribadi

Setelah naskah dibersihkan, langkah selanjutnya adalah mengukur naskah. Pengukuran naskah meliputi tinggi, lebar, dan tebal naskah. Tinggi naskah dihitung dari batas bawah naskah sampai dengan batas atas naskah. Lebar naskah dihitung dari batas kiri naskah sampai dengan batas kanan naskah. Sedangkan tebal naskah dihitung berdasarkan seberapa tebal naskah yang dimaksud. Pengukuran ini dilakukan untuk menentukan ukuran archival box yang akan dibuat.

\section{Gambar 2 \\ Ilustrasi Pengukuran Tinggi, Lebar, dan Tebal Naskah}

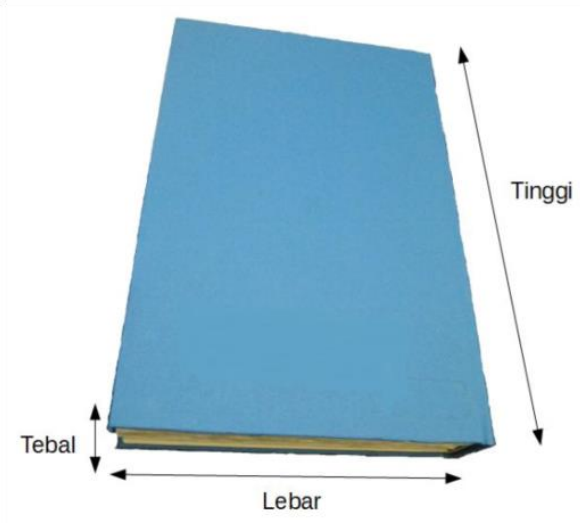

Sumber: dokumen pribadi

Setelah memperoleh ukuran naskah, langkah selanjutnya adalah membuat ukuran archival box. Penyimpanan naskah kuno ke dalam archival box menjadi penting guna menjaganya agar dapat bertahan lama. Setidaknya, penggunaan archival box diharapkan dapat menghindarkan material naskah kuno dari berbagai polutan yang dapat merusak fisik naskah tersebut (Walker, 2013).. Bahkan, Brazilian National Archives, sebagaimana dikutip oleh D'Almeida (2013), memberikan rekomendasi bahwa setiap dokumen tekstual harus disimpan di dalam archival box berukuran standar. Masalah muncul ketika archival box standar yang tersedia di pasaran memiliki ukuran yang telah ditentukan (Barron, 2017), sedangkan naskah kuno yang tersedia memiliki ukuran yang berbeda-beda.

Pembuatan archival box dalam penelitian ini tidak menggunakan ukuran standar sebagaimana telah disarankan di atas. Ukuran archival box disesuaikan dengan ukuran naskah yang akan dimasukkan. Oleh karena itu, pada tahap awal pembuatannya, hal yang perlu dilakukan adalah menentukan ukuran tinggi, lebar, dan tebal archival box yang akan dibuat.

Penentuan ukuran box dilakukan dengan menambahkan beberapa centimeter pada ukuran naskah untuk menyediakan ruang kosong. Pada artikel ini, ukuran naskah ditambahkan $3 \mathrm{~cm}$ sehingga diperoleh ukuran archival box sebagai berikut: 
Tinggi: Tinggi Naskah $+3 \mathrm{~cm}$.

Lebar: Lebar Naskah $+3 \mathrm{~cm}$.

Tebal: Tebal naskah $+3 \mathrm{~cm}$.

Setelah diperoleh ukuran yang tepat, langkah selanjutnya adalah menggambar pola archival box pada kertas trobos berukuran 3 mm. Pemilihan kertas trobos dikarenakan kertas ini merupakan salah satu kertas yang mudah diperoleh.

\section{Gambar 3 \\ Ilustrasi Pola Archival Box Pada Kertas Trobos}

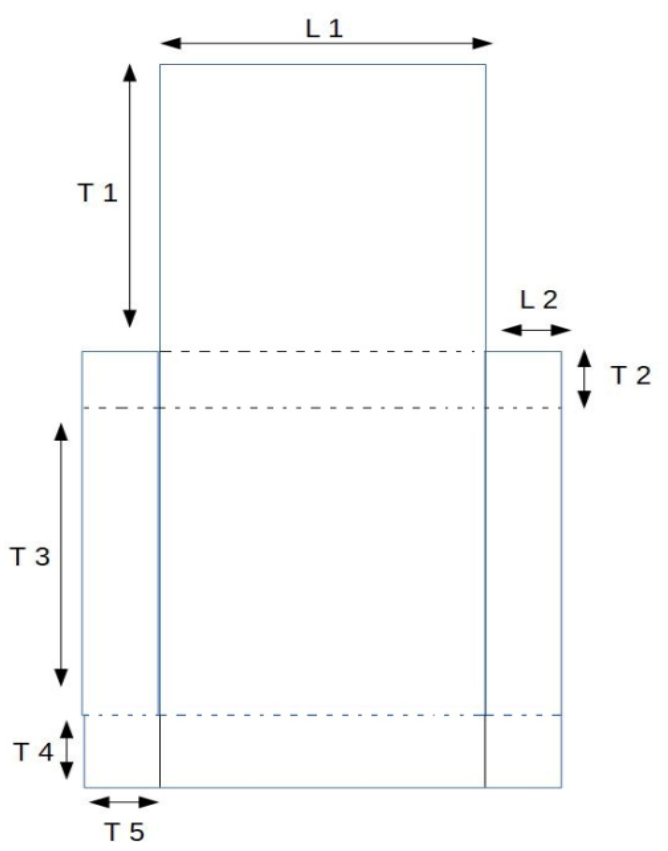

Sumber: dokumen pribadi

Keterangan:

L1 = Lebar archival box

$\mathrm{L} 2=\mathrm{T} 2=\mathrm{T} 4=\mathrm{T} 5=\mathrm{Tebal}$ archival box

T1=T3=Tinggi archival box

Langkah selanjutnya adalah memotong kertas trobos sesuai pola yang telah digambar. Setelah dipotong masing-masing sisi dilipar mengikuti pola. Agar lebih mudah, pelipatan dilakukan menggunakan bone folder.

Selain pola di atas, juga digambar pola tambahan sebagai pengait pada tutup archival box pada kertas trobos berukuran $2 \mathrm{~mm}$. Pola ini dibuat sebanyak dua buah dan memiliki ukuran lebr $3 \mathrm{~cm}$ dan panjang sama dengan panjang naskah. Nantinya pola ini akan dipotong dan dilipat menyerupai huruf L.

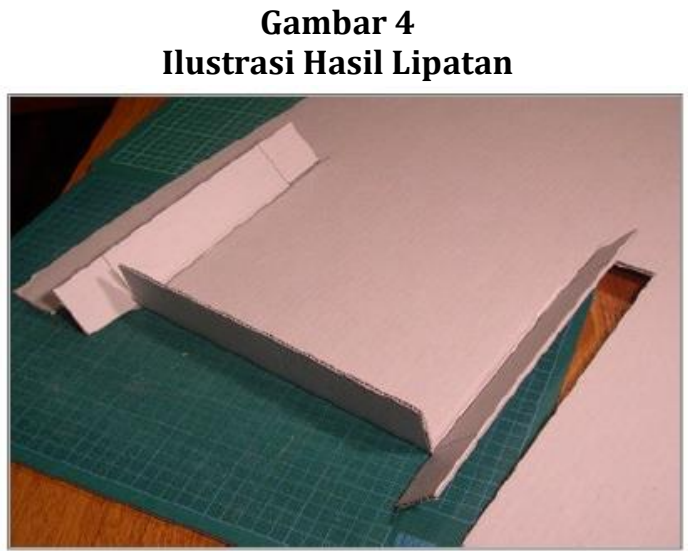

Sumber: Royal History Society of Victoria, 2017.

Gambar 5

Ilustrasi Pola Huruf L

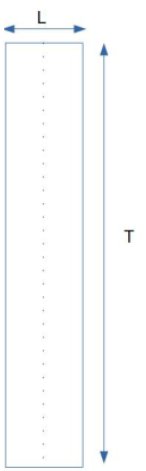

Sumber: dokumen pribadi

Selanjutnya, dilakukan perekatan masingmasing sisi archival box menggunakan lem. Pola $\mathrm{L}$ yang telah dipotong juga direkatkan pada sisi kiri dan kanan archival box. Tunggu hingga lem mengering dan masing-masing sisi telah merekat dengan sempurna.

Langkah berikutnya adalah melapisi archival box dengan kertas linen. Kertas ini merupakan kertas khusus yang telah dilapisi dengan linen sehingga membuatnya kedap air dan tidak mudah bocor. Terlebih dahulu, kertas linen dipotong sesuai dengan ukuran archival box sebelum direkatkan. 


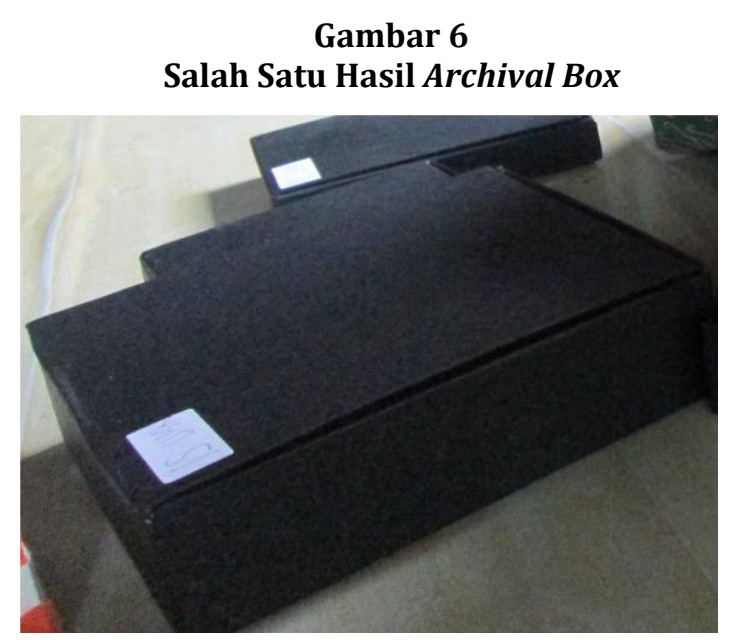

Sumber: dokumen pribadi

\section{Simpulan}

Pemaparan di atas dapat disimpulkan bahwa pembuatan archival box dapat dilakukan dengan memanfaatkan bahan-bahan sederhana yang mudah diperoleh. Penggunaan bahan tersebut merupakan proses konservasi dasar yang dapat dilakukan oleh masyarakat sebagai bentuk penyelamatan naskah yang mereka miliki. Melalui pemanfaatan bahan-bahan sederhana, diharapkan masyarakat dapat melakukan konservasi dasar tersebut secara mandiri.

\section{Ucapan Terimakasih}

Penulis mengucapkan terimakasih kepadaKementerian Riset Teknologi dan Pendidikan Tinggi Republik Indonesia yang telah menyediakan pendanaan melalui kontrak penelitian nomor: 007/KONTRAKPENELITIAN/K10/KM/2017. Tidak lupa penulis ucapkan terimakasih kepada Universitas Lancang Kuning melalui LPPM yang telah memfasilitasi jalannya penelitian ini. Penulis juga mengucapkan terimakasih kepada seluruh pihak yang ikut terlibat di dalam kegiatan penelitian ini yang tidak dapat penulis sebutkan satu persatu.

\section{Daftar Pustaka}

Barron, Sofia I. (2017). The Right Fit. Archival Product News, 21(1), 1-10.

D’Almeida, Maria Luiza Otero. (2013). Performance parameters for archival boxes. São Paulo : Instituto de PesquisasTecnológicas

Fauzan dan Baharuddin Siagian. (2017). Kamus Hukum dan Yurisprudensi. Depok: Kencana.
Iswanto, Agus. (2015). Khazanah Naskah Kuno Keagamaan Islam di Propinsi Riau: Deskripsi telaah khusus pada naskah bertemakan tauhid. Jurnal Lektur Keagamaan, 13 (2), 431- 454.

Pearce-Mose, Richard. (2005). A Glossary of Archival and Record Terminology. Chicago: The Society of American Archivist.

Prytherch, Ray. (2009). Harrod's Librarian's Glossary and Reference Book. England: Ashgate e-Book. https://doi.org/10.1108/0950412061063 8320

Redaksi Penerbit Asa Mandiri. (2007). Undangundang Perpustakaan. Jakarta: Asa Mandiri.

Royal History Society of Victoria. (2017). Making a Clamshell Box. Retreived from http://www.historyvictoria.org.au/socgui de/pdf/box2.pdf/

Stevenson, Janet dan P. H. Collin. (2006). Dictionary of Information and Library Management. London: A\&C Black.

Walker, Alison. (2013). Basic Preservation. Retrieved from https://www.bl.uk/aboutus/stratpolprog/ collectioncare/publications/booklets/basi c_preservation.pdf/.

Wan Ali Hj. Wan Mamat. (1988). Pemuliharaan Buku dan Manuskrip. Kuala Lumpur: Dewan Bahasa dan Pustaka Kementerian Pendidikan Malaysia. 